\title{
Evaluation of Deformation and Permeability Behavior of Amygdaloidal Basalt under a Triaxial Cyclic Loading Creep Test
}

\author{
Long Yan, ${ }^{1,2}$ Weiya Xu, ${ }^{1,2}$ Biao Li ${ }^{1},{ }^{1,2}$ Hua Ji, ${ }^{3}$ and Jinjian $\mathrm{Gu}^{3}$ \\ ${ }^{1}$ Key Laboratory of Ministry of Education for Geomechanics and Embankment Engineering, Hohai University, \\ Nanjing 210098, China \\ ${ }^{2}$ Institute of Geotechnical Engineering, Hohai University, Nanjing 210098, China \\ ${ }^{3}$ Huadong Engineering Corporation Limited, PowerChina, Hangzhou 310014, China \\ Correspondence should be addressed to Biao Li; libiao_1717@163.com
}

Received 14 October 2020; Revised 2 November 2020; Accepted 12 November 2020; Published 26 November 2020

Academic Editor: Zhigang Tao

Copyright (C) 2020 Long Yan et al. This is an open access article distributed under the Creative Commons Attribution License, which permits unrestricted use, distribution, and reproduction in any medium, provided the original work is properly cited.

\begin{abstract}
Amygdaloidal basalt is a typical rock mass in the dam foundation of the Baihetan hydropower project in southwest China. With rising and drawdown of the reservoir water level, the permeability and creep deformation characteristics of the amygdaloidal basalt are much complicated in the long-term cyclic loading processes. A cyclic loading-unloading creep test on the amygdaloidal basalt was performed to evaluate its deformation and permeability behavior. The results showed that Poisson's ratio and elastic modulus of the rock specimen varied significantly under different loading processes with a relatively large irreversible deformation. The permeability and strain rates of rock changed in two phases under lower deviatoric stresses, while there are three typical stages of strain growth with the final stress level of $121.8 \mathrm{MPa}$. For axial stress of $128 \mathrm{MPa}$, the creep deformation and creep rate in the axial direction are smaller than these in the lateral direction. Before the sample failure, the lateral deformation accelerates earlier than the axial deformation. The results also suggested that the permeability of the rock specimens decreases considerably during each loading process and then tends to be constant with time. No apparent change in steady permeability is observed with variation of stress. For $128 \mathrm{MPa}$ axial stress, the permeability first decreases, then tends to be in a stable value, and at last increases during the sample failure.
\end{abstract}

\section{Introduction}

Permeability and time-dependent mechanical behavior of rock are very important in rock engineering during its lifetimes, especially in powerhouse and dams, underground petroleum storage caverns, and tunnels [1-5]. The permeability of rock material is determined from laboratory experiments [6-9] and site experiments [10]. For measuring the permeability, the laboratory mainly relied on Darcy's law to measure permeability during steady-state seepage flow [11]. Some research scholars had mostly focused on the permeability measurement method, influencing factors of rock permeability, permeability under complex stress conditions, and the anisotropic permeability [12-15]. Other scholars have studied the evolution of rock permeability during creep loading $[16,17]$. For time-dependent mechanical behavior, the researchers have carried out extensive laboratory creep experiments $[5,17-19]$. The experimental results show that the main factors affecting the creep characteristics of the rock are environmental conditions, stress condition (such as deviatoric stress level, confining pressure, and pore water pressure), and microfractures of a rock specimen [5, 19-21]. The exponential function can accurately describe the relationship between the steady-state creep rate and the deviatoric stress. Similarly, confining pressure has a significant impact on the creep rate with the increasing confining pressure creep rate being reduced under the constant stress. The environmental conditions (water presence, temperature) also affect the creep characteristics of the rock.

However, the permeability and mechanical properties of rock during cyclic loading creep are still unclear. This is very important for the seepage evolution and creep characteristics of high dam foundation rock mass in the process of reservoir water level fluctuation. This study introduces the results of 


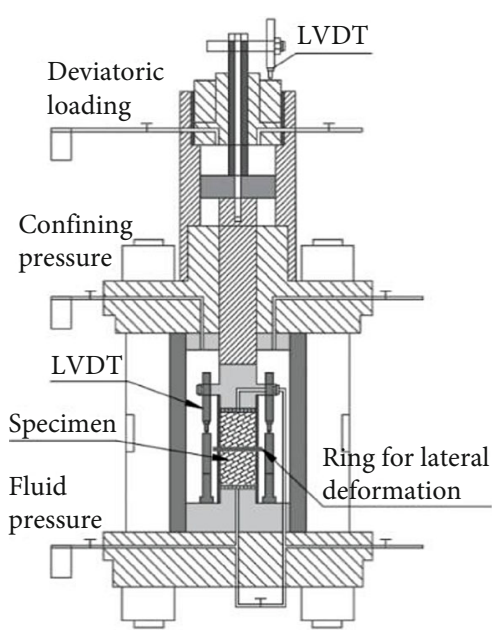

Figure 1: Device sketch of the hydro-mechanical-creep coupling triaxial system.

the cyclic loading and unloading triaxial creep test, and then, the experimental results are analyzed and discussed in detail. The results have an important theoretical significance for the seepage characteristics and time-dependent mechanical behavior during the cyclic loading and unloading creep test, which also provides test results for the long-term stability and safety research of hydropower projects.

\section{Experimental Method and Material}

The focus of this paper is to study the permeability and deformation characteristics of the amygdaloidal basalt sample during the long-term cyclic loading process. The hydromechanical-creep coupling triaxial system was used in the experiment (see Figure 1). The development and design of the rock testing system are introduced in detail by Wang et al. [13]. The system consists of three high-precision pumps for providing pressures to control confining pressure $\left(\sigma_{2}=\sigma_{3}\right)$, axial pressure $\left(\sigma_{1}\right)$, and fluid pressure $(P)$.

The following testing detail and procedure were adopted for each of the steps: (1) The prepared specimen was vacuum saturated for a period of 24 hours. (2) Install the sample and adjust the setting of LVDT sensors. (3) The confining pressure is applied to the predetermined value through the oil pressure system and remains constant during the experiment. (4) After the confining pressure remains stable, the seepage pressure is applied. In this experiment, the predetermined value of the upstream end of the specimen is $2.0 \mathrm{MPa}$, and the downstream end is exposed to the atmospheric pressure. (5) To retain 24 hours under confining pressure of 6.0 $\mathrm{MPa}$ and seepage pressure of $2.0 \mathrm{MPa}$, the permeability of the sample remains essentially unchanged and the axial deviatoric stress was applied under stress control at a constant rate of $0.075 \mathrm{MPa} / \mathrm{s}$. The rate of unloading is consistent with the loading process. The stress path was applied in the loading-unloading triaxial creep testing of the sample as illustrated in Figure 2.

The permeability of rock was measured by a steady-state method in cycle loading and unloading creep processes. The permeability of rock can be expressed by Equation (1), and

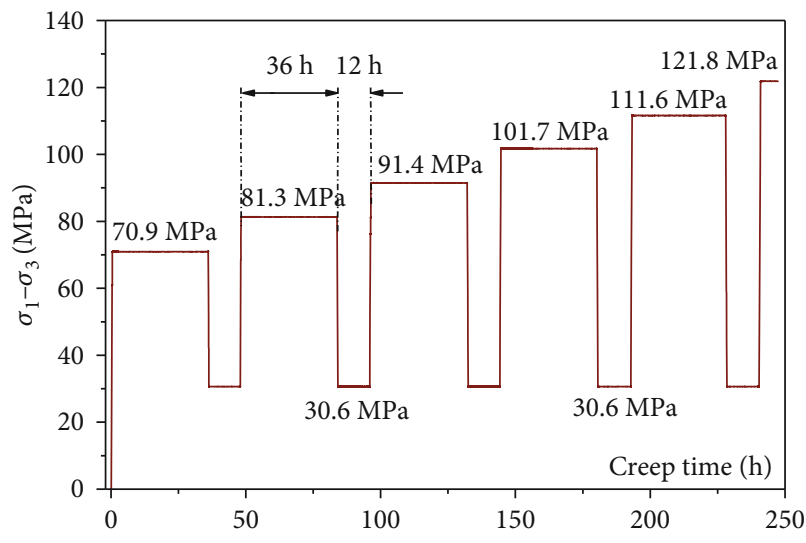

FIgURe 2: Multilevel loading and unloading stress path applied in the triaxial creep testing.

the formula is based on Darcy's law and calculated the volume of water in the pump as it changes with time [14]:

$$
K=\frac{\mu L V}{A \Delta P \Delta t}
$$

where $K$ is the permeability of the rock specimen $\left(\mathrm{m}^{2}\right) ; V$ is the flow volume through the specimen during the experiment $\left(\mathrm{m}^{3}\right) ; \Delta P$ is the pore pressure difference between the upper and lower ends of the sample $(\mathrm{Pa}) ; L(\mathrm{~m})$ and $A\left(\mathrm{~m}^{2}\right)$ are the length and cross-sectional area of the sample, respectively; $\mu$ is the dynamic viscosity of water at $20^{\circ} \mathrm{C}$ and $\mu=$ $10^{-3} \mathrm{~Pa} \bullet \mathrm{s}$; and $\Delta t$ is the time interval (s).

Amygdaloidal basalt is a typical dam foundation rock mass of the Baihetan hydropower station. The tested specimen was prepared according to the IRSM [22] recommendations, and the standard cylindrical specimen of $50 \mathrm{~mm}$ in diameter and $100 \mathrm{~mm}$ in height is shown in Figure 3(a).

The main reason of amygdaloidal basalt formation is the deposition of secondary minerals; during the cooling process, calcite and quartz trapped are in the interior of the rock. There are many cavities in the lava process, called amygdales, the color of which is usually white. When the cavities are filled with calcite and quartz, the structure is called amygdaloidal basalt.

Using scanning electron microscopy, the microscopic pore distribution of the amygdaloidal basalt sample enlarged 500 times and 2000 times are obtained as shown in Figures 3(c) and 3(d). The tested amygdaloidal basalt has classical granular structures, and the micropores, irregularly arranged mineral particles, and irregular lump in shape can be seen clearly in SEM photos. Compared to other basalt, amygdaloidal basalt has the characteristics of high porosity and low strength.

\section{Experimental Results and Discussion}

3.1. The Stress-Strain Curves during the Creep Test. Figure 4 shows stress-strain curves of the sample under $\sigma_{3}=6 \mathrm{MPa}$ and $\Delta P=1.9 \mathrm{MPa}$. The stress-strain curves are described in detail in the following stages: 


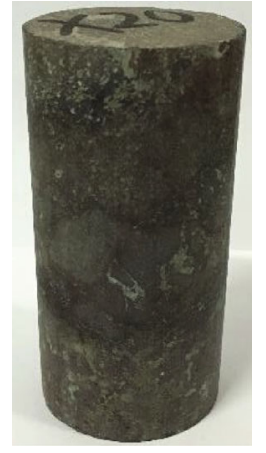

(a)

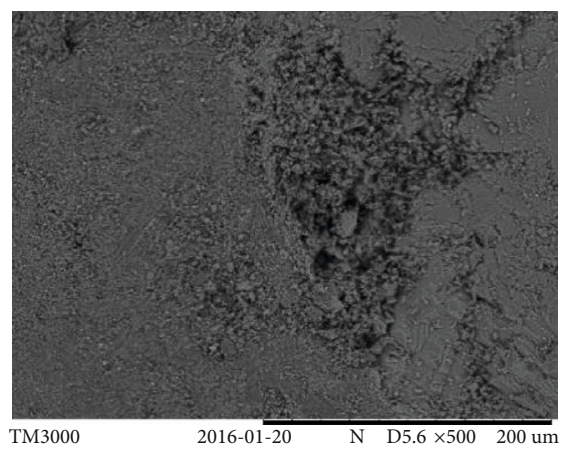

(c)

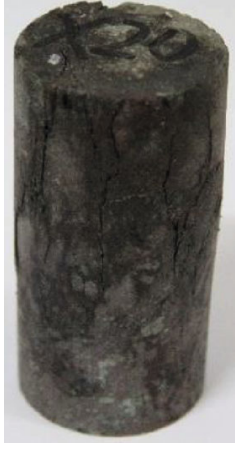

(b)

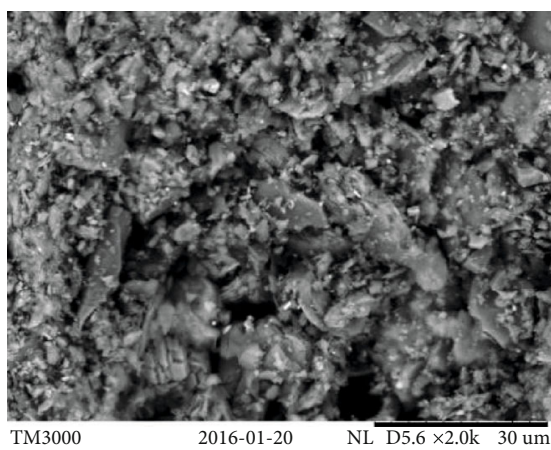

(d)

FIGURE 3: Characterization of amygdaloidal basalt sample: (a) specimen before the test; (b) specimen after macroscopic failure; (c) microstructure of the amygdaloidal basalt sample in SEM: magnified 200 times; (d) microstructure of the amygdaloidal basalt sample in SEM: magnified 2000 times.

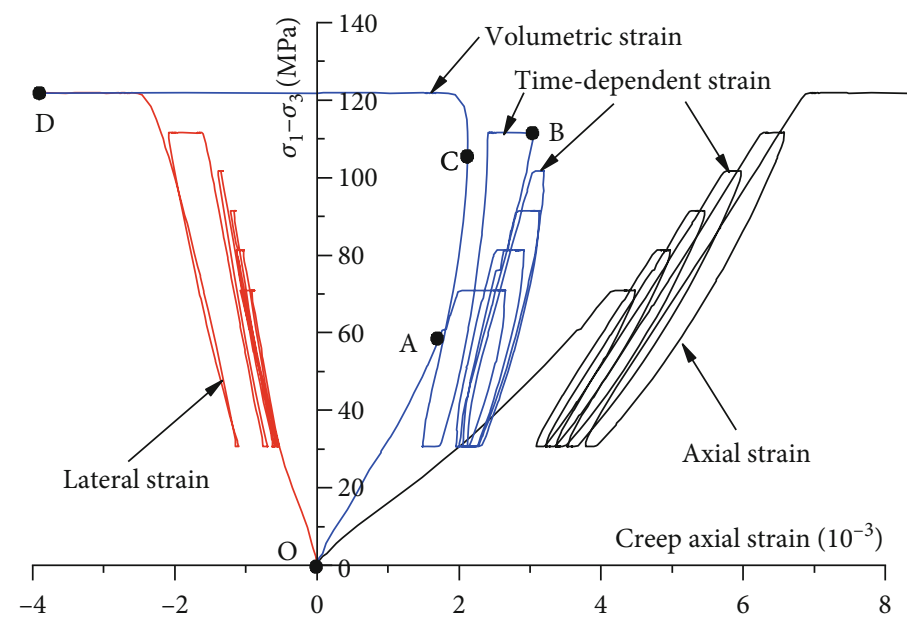

FIGURE 4: Stress-strain curves during a multilevel cycle loading-unloading triaxial creep test $\left(\sigma_{3}=6 \mathrm{MPa}, \Delta P=1.9 \mathrm{MPa}\right)$.

(1) Crack Closure (OA). This stage occurs only during the first loading process. Because of the preexisting microcracks into the specimen, the stress-strain curves present a nonlinear characteristic in the initial loading process, when the deviatoric stress applied to the specimen reaches $53 \mathrm{MPa}$ (A point) and the microcracks and micropores in the rock are completely closed.

(2) Elastic Deformation $(A B)$. The rock deformation enters this stage (starting from point $\mathrm{A}$ ) and the stress-strain curves to exhibit linear elastic characteristics. At this stage, we can consider that the rock sample is still in an elastic state for both loading and unloading processes, and there is no new microscopic damage into the sample during this process. However, with the increasing deviatoric stresses, the time characteristics of the sample as well as its rheological properties under different stress levels were obvious. During the previous four loading processes, the deformation of the sample is still at the elastic stage. As general compaction, the axial strains (instantaneous and rheological) are greater than the lateral strain. 


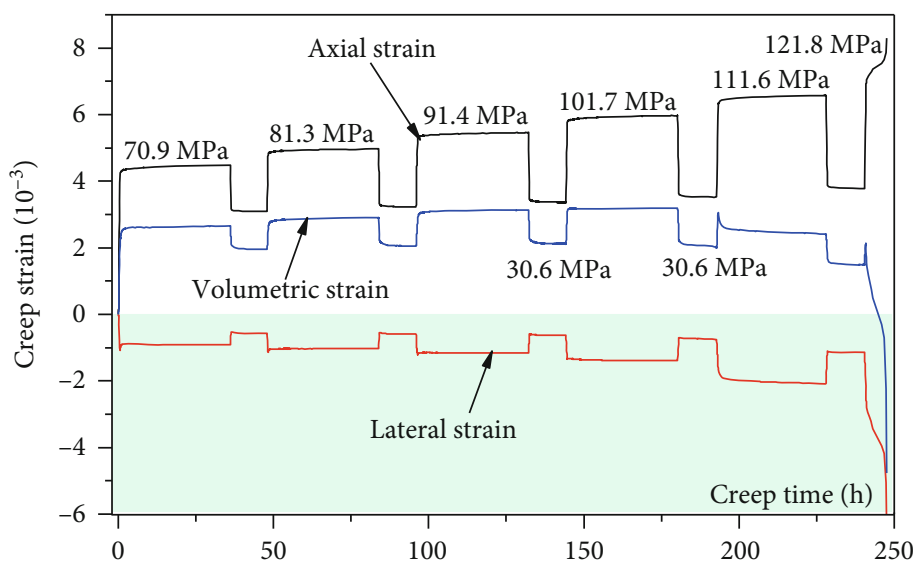

Figure 5: Strain-time curves $\left(\sigma_{3}=6 \mathrm{MPa}, \Delta P=1.9 \mathrm{MPa}\right)$.

TABLE 1: The axial strain of deviatoric stress of $30.6 \mathrm{MPa}$ during cycle loading.

\begin{tabular}{lcccccc}
\hline No. & 0 & 1 & 2 & 3 & 5 \\
\hline Axial strain $\left(10^{-3}\right)$ & 2.001 & 3.091 & 3.230 & 3.372 & 3.526 & 3.783 \\
Increased amplitude $\left(10^{-3}\right)$ & - & 1.090 & 0.139 & 0.142 & 0.154 & 0.257 \\
\hline
\end{tabular}

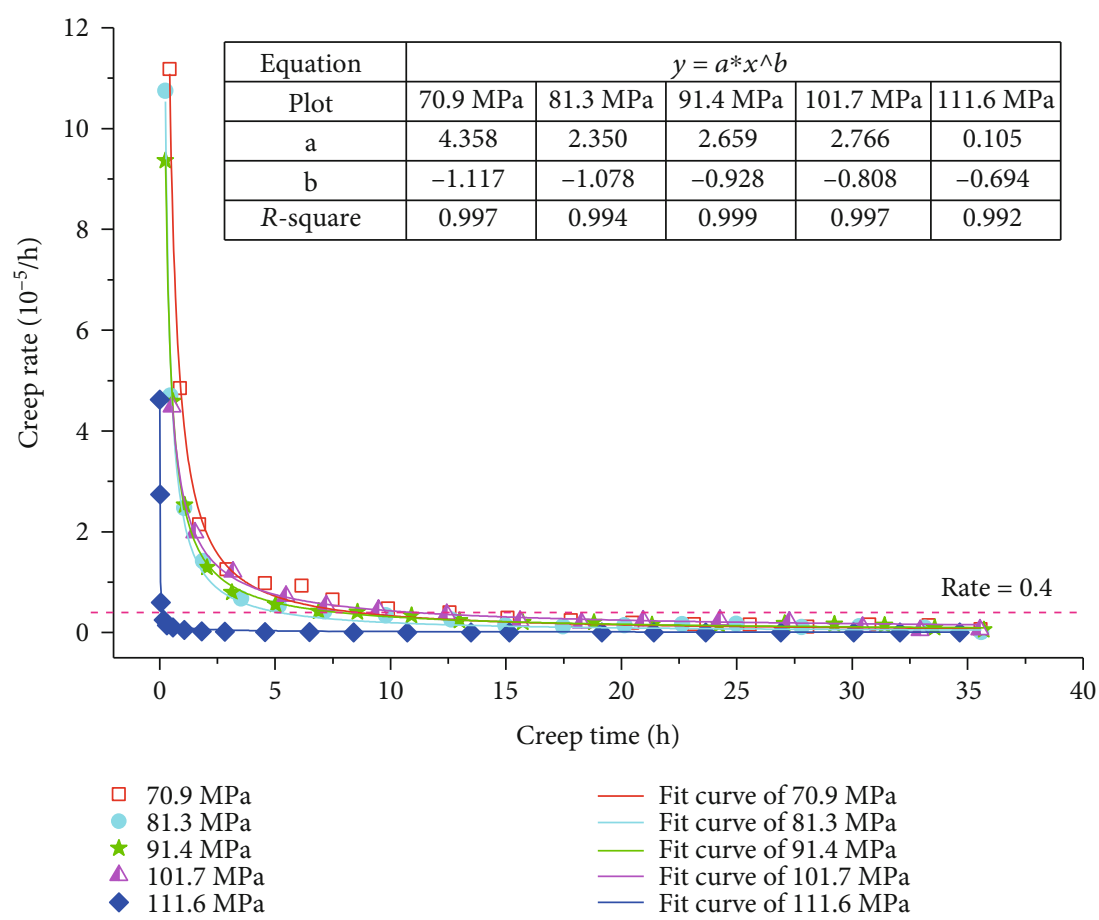

Figure 6: The evolution laws of the axial strain creep rate and time under deviatoric stresses.

In the linear elastic phase of the stress-strain curves, Young's modulus and Poisson's ratio at different loading stages can be calculated. The elastic modulus of the specimen is about 28.61-29.61 GPa in the process of loading-unloading. In the first five loading-unloading cycles, Poisson's ratio ranges from 0.23 to 0.26 , but in the last loading process, Poisson's ratio is 0.33 .
(3) Nonlinear Strain Phase (BC). For $111.6 \mathrm{MPa}$ deviatoric stress level, in view of the long-term accumulation of the rheological effect, the lateral strain increases gradually with time when the deviatoric stress remains constant. Thus, in this rheological process, the lateral strain of the specimen is more sensitive and greater than the axial strain. Meanwhile, there 


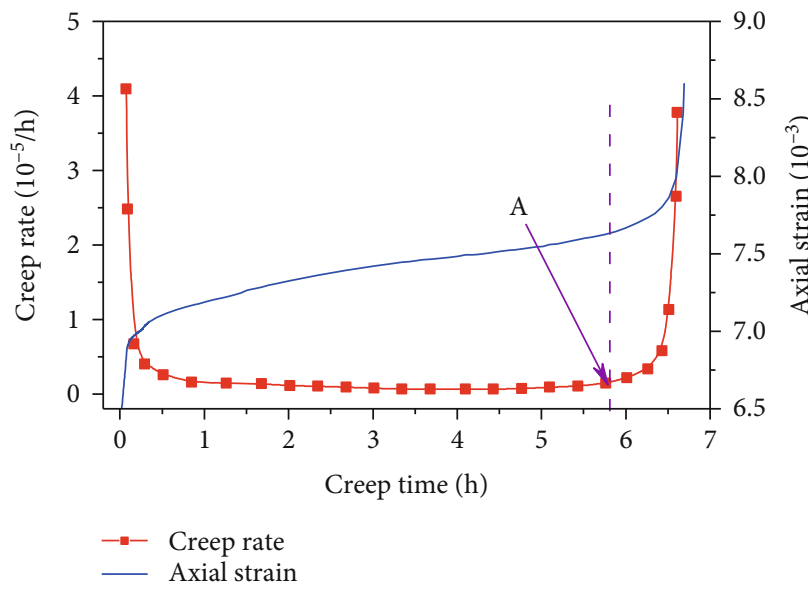

(a)

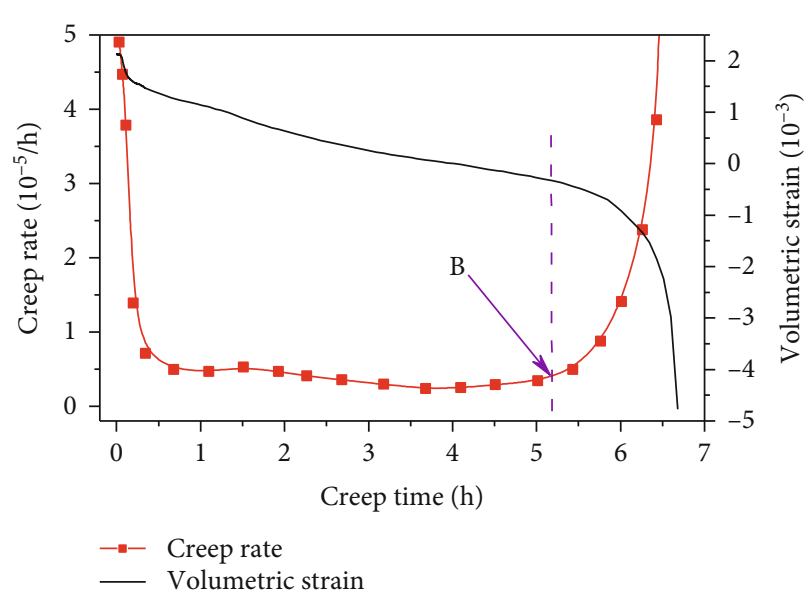

(b)

FIGURE 7: Creep strain and rate versus time under $\sigma_{3}=6 \mathrm{MPa}$ and $\Delta P=1.9 \mathrm{MPa}$ : (a) axial strain and rate versus time and (b) volumetric strain and rate versus time.

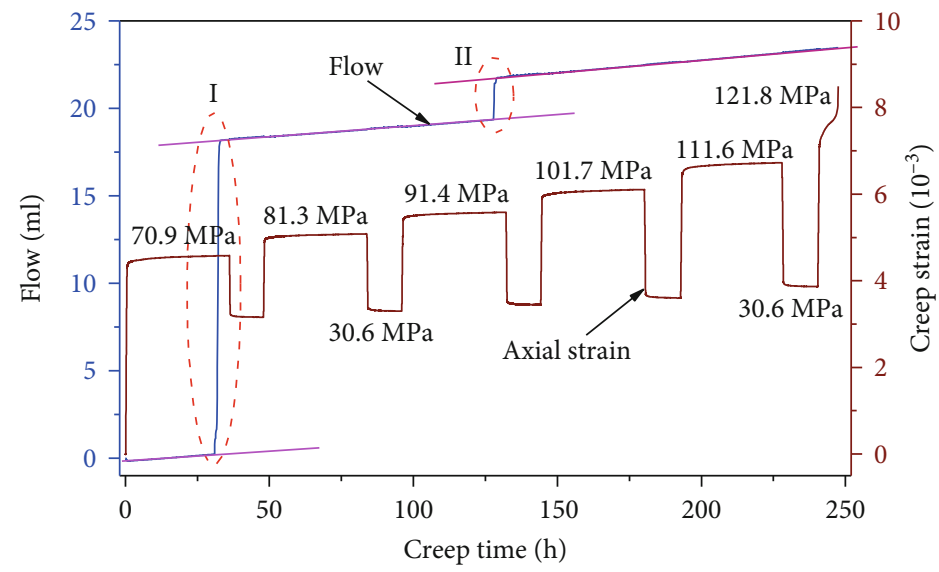

FIgURE 8: Triaxial multistage creep-seepage test result.

are new microcracks in the sample which gradually stabilize the expansion during this stage.

(4) Unstable Crack Growth (CD). During the last loading to $104 \mathrm{MPa}$ (85.4\% of the failure stress), the volumetric strain appeared in the turning point $(\mathrm{C})$ and entered the microcrack generation and expansion stage. In this stage, the sample volumetric strain is mainly caused by lateral strain.

3.2. Time-Dependent Strain of the Sample. Figure 5 shows the curves of creep strain change with time. The creep deformation increased smoothly, which means that the creep strains of this sample have good continuity with time. For low deviatoric stresses, the curves have two stages (decelerated and steady creep stages). In this experiment, the last deviatoric stress level is $121.8 \mathrm{MPa}$, the sample has a typical threestage creep (decelerated stage, steady stage, and increasing creep stage) in this deviatoric stress level, and the failure of the sample occurs after the last loading for $6.5 \mathrm{~h}$.

The overall trend of volumetric strain and lateral strain are similar to that of the axial strain. Before failure, the initial creep and steady creep phenomenon of the sample is obvious, which has the same varying tendency under different deviatoric stresses. When the deviatoric stress of the specimen exceeds the capacity of the rock material, the rate of volumetric strain is obviously greater than the axial strain rate. With the increase in deviatoric stress, the original defects (micropores and microcracks) of the sample are compressed to the minimum. Thereafter, when the deviatoric stress reaches the fifth-order stress level $(111.6 \mathrm{MPa})$, the deformation occurs mainly in the circumferential direction, and the lateral strain is more significant than the increase in the axial strain (in Figure 4).

By comparing the strain-time relationship at different deviatoric stress levels, we can see that the increase in deviatoric stress accelerates the occurrence of creep strain. When the deviatoric stress is unloaded to $30.6 \mathrm{MPa}$, a considerable part of irreversible deformation occurs because of rheological effects. With the increase in deviatoric stress, the residual deformation occurs also after unloading the stress to 30.6 MPa. Take the axial train as an example, the axial strain is 2.001 at the first loading to $30.6 \mathrm{MPa}$. After the five 


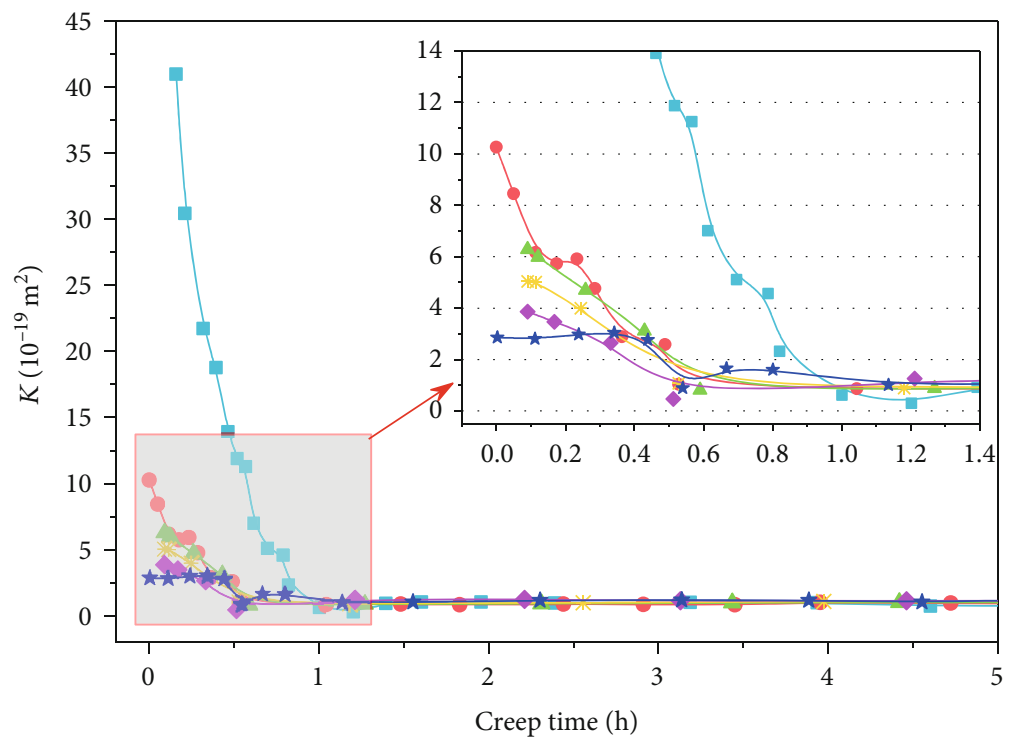

Stress level (MPa)

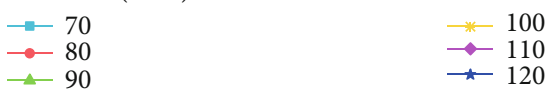

Figure 9: Permeability variation at different stress levels during the loading phase.

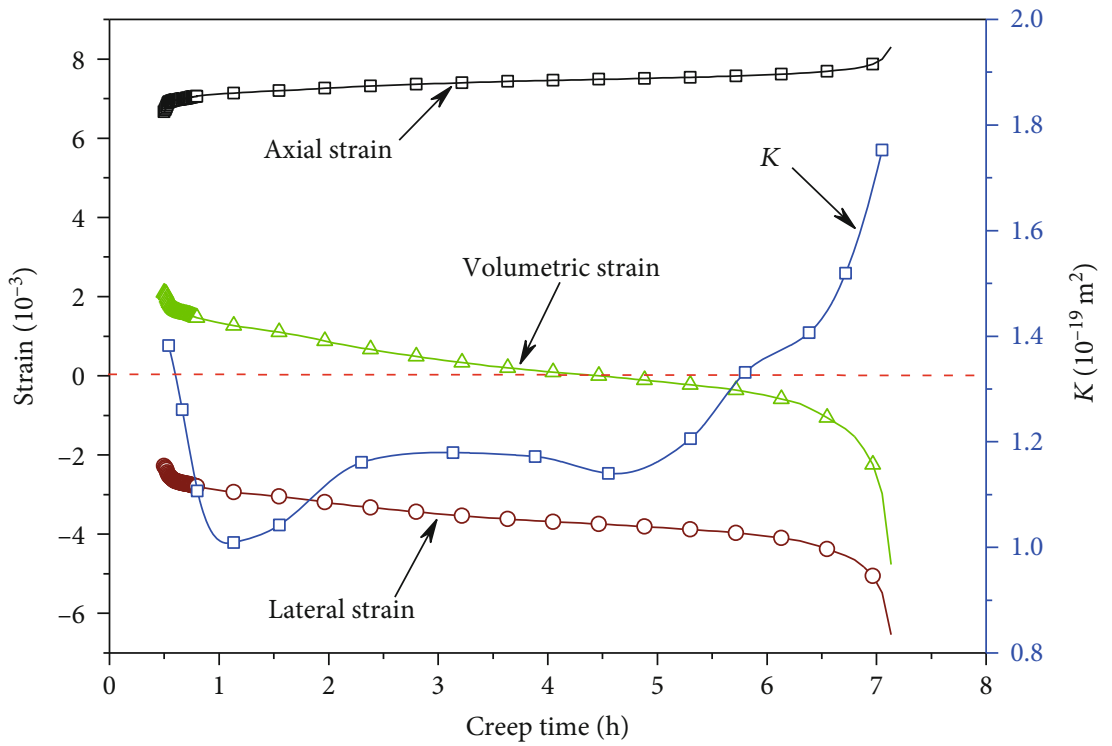

FIGURE 10: Creep-seepage test result at the final deviatoric stress level.

unloading processes, when unloading to $30.6 \mathrm{MPa}$, the values of axial strain are 3.091, 3.230, 3.372, 3.526, and 3.783, respectively (in Table 1 ). The increased amplitude of axial strain increases with the increasing loading cycles (at the 2nd to 5th unloading processes), which implied that with the increase in deviatoric stress and creep time, the viscoplastic strains present a nonlinear increasing trend.

3.3. Strain Rate Analysis. The rock's creep rate is an important index in stability to evaluate long-term stability of rock engineering. Figure 6 shows that in the low deviatoric stress levels, the rock's creep rate also shows two stages: decelerated stage and steady creep stage. When the deviatoric stress loading was stopped, the creep rate quickly reduces with time and trends to be a constant value, which explains that the sample's creep is in a steady creep stage, but the deformation of rocks still grows during this stage. For the creep deformation for 10 hours after loading, the axial strain creep rate is less than $0.4 \times 10^{-5} / \mathrm{h}$ under different deviatoric stresses.

From Figures 7(a) and 7(b), it can be seen that in the final stress level $(121.8 \mathrm{MPa})$, the volumetric and axial creep rates show different behaviors in comparison with those of the 


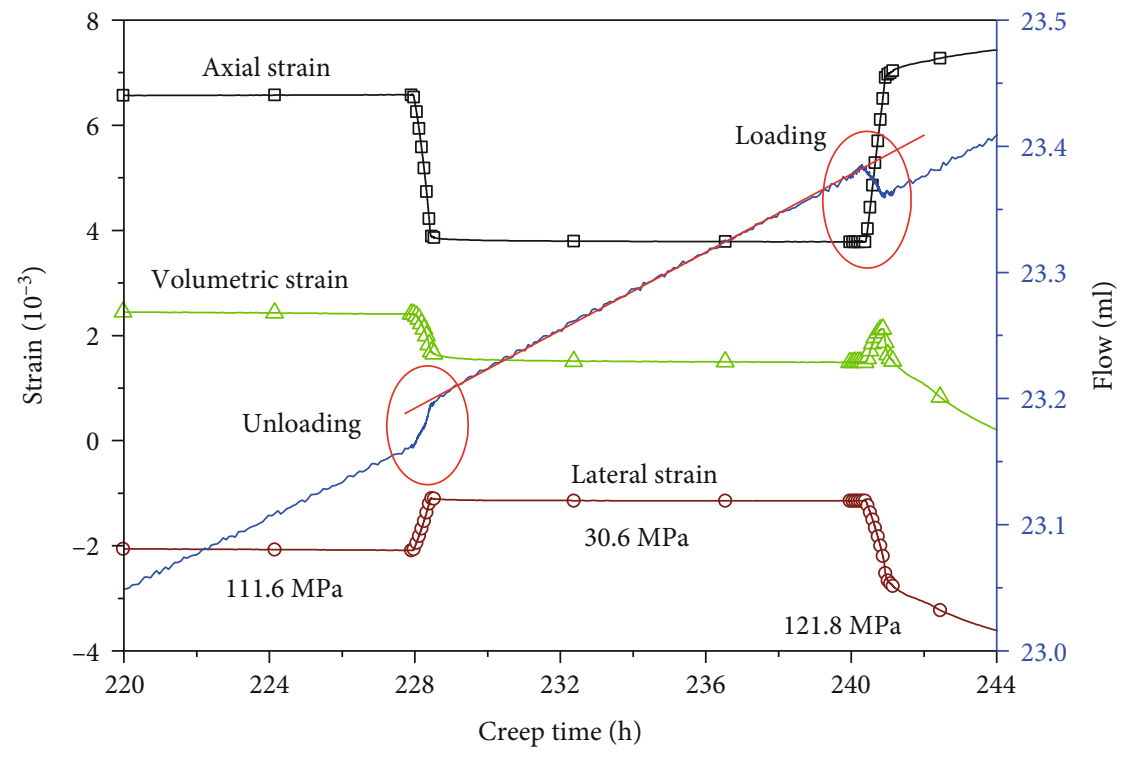

FIGURE 11: The relationship between the seepage flow and creep strain versus time during loading and unloading stages.

former stress levels, and the typical three-stage creep is observed at this stress level. In the steady creep stage of the final stress level, the axial strain and volumetric creep rates are about $0.061 \times 10^{-5} / \mathrm{h}$ and $0.233 \times 10^{-5} / \mathrm{h}$, respectively.

The creep rate of volumetric strain is larger than the axial creep rate in the last stress level, and the main reason is that large deformation occurs in the radial direction of the sample. From Figure 7, each creep strain rate-time curve has an obvious inflection point (points A and B in Figure 7) which indicates that the creep stage changes from a steady creep stage to an increasing creep stage, and the rock sample tends to fail. Meanwhile, we can see that the time of the inflection point of the volumetric creep rate is earlier than that of the axial creep rate, which means that the lateral deformation acceleration of the specimen before the failure is earlier than that of axial deformation.

3.4. Permeability Evolution during the Creep Test. Figure 8 shows the relationship between the seepage flow and the axial strain versus time. It can be found that there are two jumps in the cumulative seepage curve during the creep process, and there is no sudden change in the axial pressure and strains during the two jumps. This indicates that the jump is not the real permeability of the specimen. In the steady-state creep process, the magnitude of permeability is $10^{-19} \mathrm{~m}^{2}$.

During the transient loading stage, the preexisted microcracks and micropores are compressed and closed due to the increase in deviatoric stress, and the permeability of the testing sample decreases with the increase in stress (as shown in Figure 9). Before applying deviatoric stress, most of the microcracks and micropores of the porous material are not connected, and the seepage pattern is mainly pore flow; the initial permeability is $45.5 \times 10^{-19} \mathrm{~m}^{2}$. After about 1 hour from the end of the first loading $(70.9 \mathrm{MPa})$, the permeability decreased from the initial $45.5 \times 10^{-19} \mathrm{~m}^{2}$ to about $0.5 \sim 2$ $\times 10^{-19} \mathrm{~m}^{2}$ and then tended to be stable. However, reaching this steady value only takes $0.5 \mathrm{~h}$ at the end of the other loading (81.3 MPa, 91.4 MPa, 101.7 MPa, 111.6 MPa, and 121.8 MPa). The permeability coefficients at the beginning of each loading process are getting lower and lower with the increase in deviatoric stress, and the coefficients of permeability decrease from $10.3 \times 10^{-19} \mathrm{~m}^{2}$ to $6.3 \times 10^{-19} \mathrm{~m}^{2}$, $5.0 \times 10^{-19} \mathrm{~m}^{2}, 3.9 \times 10^{-19} \mathrm{~m}^{2}$, and $2.9 \times 10^{-19} \mathrm{~m}^{2}$, when the deviatoric stress increases from $81.3 \mathrm{MPa}$ to $91.4 \mathrm{MPa}$, 101.7 MPa, 111.6 MPa, and121.8 MPa accordingly. The phenomenon that the material strengthens under cyclic loading and unloading before the yield of the rock material can be explained.

At the last level of the deviatoric stress, the microcracks in the sample are continuously expanding over time to form a macroscopic fracture, which led to rock sample failure under the cyclic loading process [23]; before the sample is completely destroyed, the permeability coefficient increases to $1.7 \times 10^{-19} \mathrm{~m}^{2}$ (see Figure 10 ). Even after failure, the permeability did not increase significantly. Figure 3(b) shows the specimen after macroscopic failure. This explains that the macroscopic failure surface does not completely pass through the longitudinal axial direction of the specimen, but only half of it, so the permeability is maintained at a relatively low level even after macroscopic failure.

Figure 11 shows the relationship between the seepage flow and creep strain during unloading (deviatoric stress from 111.6 $\mathrm{MPa}$ to $30.6 \mathrm{MPa}$ ) and loading (deviatoric stress from $30.6 \mathrm{MPa}$ to $121.8 \mathrm{MPa}$ ). The seepage flow changed significantly in the moment when the deviatoric stress increases or decreases. When deviatoric stress decreases from 111.6 $\mathrm{MPa}$ to $30.6 \mathrm{MPa}$, the reason is that the decrease in deviatoric stress compresses the rock sample crack so that the seepage flow is increased. Conversely, some microcracks reclose with the increase in deviatoric stress, so we can see that the seepage flow is reduced. The slope of the seepage flow did not change significantly before and after the change of 
deviatoric stress (in Figure 11), there is no obvious change in permeability during the deviatoric stress change, and the permeability magnitude of the sample is $10^{-19} \mathrm{~m}^{2}$. The main reason is that there are no obvious cracks in the rock sample before failure.

\section{Conclusion}

In this research, through the triaxial cyclic loading and unloading creep test, Young's modulus and Poisson's ratio of the amygdaloidal basalt sample at different loading stages can be obtained; these values are varied rather than a fixed value. The creep deformation and creep rate all demonstrate two stages (decreasing phase and steady phase) when the deviatoric stress is less than the yield stress. And a considerable part of irreversible deformation occurred during the loading creep processes. The permeability of amygdaloidal basalt undergoes an evident decrease during each loading process and then tends to be in a constant value during the steady creep phase. For the final deviatoric stress level, the permeability first decreases, then tends to be in a stable value, and at last increases during the sample failure. The permeability of the material is related not only to the porosity and microcrack distribution but also to the stress environment. When the deviatoric stress level is $121.8 \mathrm{MPa}$, a large deformation occurs in the radial direction and the lateral deformation accelerates earlier than the axial deformation before rock failure; the creep strain increases at an increasing rate until the rock sample failure. This research does not discuss more about the influence of confining pressure and permeable pressure on the permeability of this rock material under cyclic loading and unloading creep processes, and future work will be done on this part.

\section{Data Availability}

The data that support the findings of this study are available from the corresponding author upon request.

\section{Conflicts of Interest}

The authors declare that they have no conflicts of interest.

\section{Acknowledgments}

This work was financially supported by the National Key R\&D Program of China (Grant No. 2017YFC1501100), the China Postdoctoral Science Foundation (2019M661711), the Fundamental Research Funds for the Central Universities (B200202083), and the National Natural Science Foundation of China (Grant No. 51939004).

\section{References}

[1] B. Mishra and P. Verma, "Uniaxial and triaxial single and multistage creep tests on coal-measure shale rocks," International Journal of Coal Geology, vol. 137, pp. 55-65, 2015.

[2] J.-F. Shao, Q.-Z. Zhu, and K. Su, "Modeling of creep in rock materials in terms of material degradation," Computers and Geotechnics, vol. 30, no. 7, pp. 549-555, 2003.
[3] J. Wang, Y. Zhang, Z. Qin, S. Song, and P. Lin, “Analysis method of water inrush for tunnels with damaged waterresisting rock mass based on finite element method-smooth particle hydrodynamics coupling," Computers and Geotechnics, vol. 126, p. 103725, 2020.

[4] J. Zhang, W. B. Standifird, J. C. Roegiers, and Y. Zhang, "Stress-dependent fluid flow and permeability in fractured media: from lab experiments to engineering applications," Rock Mechanics and Rock Engineering, vol. 40, no. 1, pp. 321, 2007.

[5] Z. Zhang, W. Xu, W. Wang, and R. Wang, "Triaxial creep tests of rock from the compressive zone of dam foundation in Xiangjiaba Hydropower Station," International Journal of Rock Mechanics and Mining Sciences, vol. 50, pp. 133-139, 2012.

[6] D. Liu, Z. Gu, R. Liang et al., "Impacts of pore-throat system on fractal characterization of tight sandstones," Geofluids, vol. 2020, 17 pages, 2020.

[7] J. Stormont and J. Daemen, "Laboratory study of gas permeability changes in rock salt during deformation," International Journal of Rock Mechanics and Mining Sciences \& Geomechanics Abstracts, vol. 29, no. 4, pp. 325-342, 1992.

[8] H. Wang, W. Xu, J. Shao, and F. Skoczylas, "The gas permeability properties of low-permeability rock in the process of triaxial compression test," Materials Letters, vol. 116, pp. 386388, 2014.

[9] W. L. Zhu and T.-f. Wong, "The transition from brittle faulting to cataclastic flow: permeability evolution," Journal of Geophysical Research: Solid Earth, vol. 102, no. B2, pp. 30273041, 1997.

[10] W. L. Taylor and D. D. Pollard, "Estimation of in situ permeability of deformation bands in porous sandstone, Valley of Fire, Nevada," Water Resources Research, vol. 36, no. 9, pp. 2595-2606, 2000.

[11] S. Baraka-Lokmane, "Hydraulic versus pneumatic measurements of fractured sandstone permeability," Journal of Petroleum Science and Engineering, vol. 36, no. 3-4, pp. 183-192, 2002.

[12] C. David, T. F. Wong, W. Zhu, and J. Zhang, "Laboratory measurement of compaction-induced permeability change in porous rocks: implications for the generation and maintenance of pore pressure excess in the crust," Pure and Applied Geophysics, vol. 143, no. 1-3, pp. 425-456, 1994.

[13] H. L. Wang, W. Xu, and J. F. Shao, "Experimental researches on hydro-mechanical properties of altered rock under confining pressures," Rock Mechanics and Rock Engineering, vol. 47, no. 2, pp. 485-493, 2014.

[14] W. Wang, W. Xu, R. Wang, C. Yj, H. Wang, and F. Sr, "Permeability of dense rock under triaxial compression," Chinese Journal of Rock Mechanics and Engineering, vol. 34, pp. 4047, 2015.

[15] N. Zisser and G. Nover, "Anisotropy of permeability and complex resistivity of tight sandstones subjected to hydrostatic pressure," Journal of Applied Geophysics, vol. 68, no. 3, pp. 356-370, 2009.

[16] Z. Liu, J. Shao, S. Xie, and J. Secq, "Gas permeability evolution of clayey rocks in process of compressive creep test," Materials Letters, vol. 139, pp. 422-425, 2015.

[17] W. Xu, R. Wang, W. Wang, Z.-l. Zhang, J.-c. Zhang, and W. Wang, "Creep properties and permeability evolution in triaxial rheological tests of hard rock in dam foundation," 
Journal of Central South University, vol. 19, no. 1, pp. 252-261, 2012.

[18] Y. Liu, C. Liu, Y. Kang, D. Wang, and D. Ye, "Experimental research on creep properties of limestone under fluid-solid coupling," Environmental Earth Sciences, vol. 73, no. 11, pp. 7011-7018, 2015.

[19] L. Ma and J. Daemen, "An experimental study on creep of welded tuff," International Journal of Rock Mechanics and Mining Sciences, vol. 43, no. 2, pp. 282-291, 2006.

[20] B. Chen, S. Zhang, Y. Li, Z. Li, and H. Zhou, "Physical simulation study of crack propagation and instability information discrimination of rock-like materials with faults," Arabian Journal of Geosciences, vol. 13, no. 18, p. 966, 2020.

[21] Z. Y-1, P. Cao, W.-j. Wang, W. Wan, and L. Y-k, "Viscoelastoplastic rheological experiment under circular increment step load and unload and nonlinear creep model of soft rocks," Journal of Central South University of Technology, vol. 16, pp. 488-494, 2009.

[22] R. Ulusay and International Society for Rock Mechanics, Commission on Testing Methods, "The complete ISRM suggested methods for rock characterization, testing and monitoring: 1974-2006," 2007.

[23] C. Yd, L. Dm, J. P. Mathews et al., "Permeability evolution in fractured coal-combining triaxial confinement with X-ray computed tomography, acoustic emission and ultrasonic techniques," International Journal of Coal Geology, vol. 122, pp. 91-104, 2014. 